\title{
DUALISMO SOCRÁTICO
}

\author{
Javier Echeñique Sosa \\ Departamento de Humanidades, Universidad Andrés Bello \\ javier.echenique@unab.cl
}

\begin{abstract}
Resumen / ABSTRACT
Este artículo se propone mostrar, en contra de las interpretaciones dominantes, que Platón debió tempranamente postular la supervivencia del alma como un sujeto independiente de daño y beneficio moral con el objeto de completar su defensa de la ética socrática - en particular el principio de Soberanía de la Virtud, central en diálogos tempranos como la Apología, el Critón y el Gorgias. Al dualismo metafísico que resulta de este postulado le denomino 'dualismo socrático', para diferenciarlo del dualismo maduro expuesto por Platón en el Fedón.
\end{abstract}

Palabras clave: alma, beneficio, cuerpo, daño, dualismo, ética, Sócrates, supervivencia, virtud.

\section{SOCRATIC DUALISM}

The purpose of this article is to show, against the dominant interpretations, that earlier in his career Plato saw the need to postulate the survival of the soul as an independent locus of benefit and harm, in order to complete his defense of Socratic ethics - in particular, of the principle of Sovereignty of Virtue, crucial to earlier dialogues such as Apology, Crito, and Gorgias. The dualism resulting from this postulate I call 'socratic dualism', distinct from the mature dualism developed by Plato in the Phaedo.

KEYWORDS: Soul, benefit, body, harm, dualism, ethics, Socrates, survival, virtue. En la historia de la filosofía, el nombre de Platón está indisolublemente asociado
al dualismo metafísico en cuanto teoría acerca de la naturaleza del ser humano,
es decir, a la idea de que el ser humano es un compuesto de dos entidades, cada una de
las cuales puede gozar de existencia 'separada' de la otra. La forma que esta idea toma
en el Fedón es sin duda la más célebre: "una parte de nosotros es el cuerpo, otra parte
es el alma" (Phd. 79b1-2)*, y cada una de estas partes puede en principio "separarse"
la una de la otra, como en la muerte (64c4-5).

Las abreviaturas de obras de Platón aquí empleadas son las siguientes: $A p$. (Apología), Cri. (Critón), Grg. (Gorgias), Phd. (Fedón), R. (República), Lg. (Leyes). 
El cuerpo aparece en el Fedón como el sujeto que padece apetitos y placeres asociados a la comida y a la bebida, como el sujeto de las emociones, y el responsable de la percepción sensorial; mientras que el alma es presentada como el sujeto de la facultad privilegiada del entendimiento ( $\delta$ ióvor $\alpha$ ), la única que nos permite el acceso cognitivo directo a las realidades formales y por ende a los fundamentos últimos del conocimiento (Phd. 64d-65e). El Fedón argumenta primero que en su problemática asociación con el cuerpo, durante la vida terrenal, el alma es incapaz de ejercer la actividad intelectual que le es propia, pues no solo debe ella atender constantemente a los apetitos, emociones y enfermedades corporales, sino que debe además conformarse con las opiniones confusas de los sentidos perceptuales; de modo que la única posibilidad de que ella ejerza adecuadamente su peculiar actividad intelectual es después de la muerte: "solamente entonces, y no antes, estará el alma por su propia cuenta separada del cuerpo

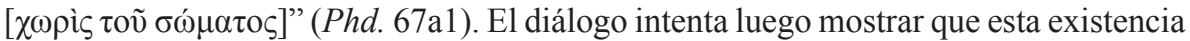
anímica separada, y caracterizada esencialmente por el ejercicio puro del entendimiento no es solo una posibilidad, sino que es un postulado que necesariamente se sigue de la hipótesis de que existen las realidades formales y el conocimiento formal que las tiene por objeto $^{1}$. Si existen las realidades formales y su conocimiento es posible, el alma humana definida por la facultad del entendimiento ha de ser capaz de existencia separada del cuerpo, pues solo así puede ella entrar en comunión con las realidades formales, cuya simplicidad e inteligibilidad comparte con ellas.

Esta es sin lugar a dudas la concepción dualista que la tradición ha identificado con Platón. Pocos están familiarizados, sin embargo, con aquella concepción dualista del ser humano que sirve a un proyecto completamente distinto, un proyecto que no dice relación con el proyecto epistémico del Fedón, el proyecto de fundamentar la posibilidad del conocimiento universal y objetivo que según este diálogo solamente puede alcanzar el alma en su comunión solitaria con las Formas. Esta otra concepción dualista, que aquí pretendo exhibir, sirve a un proyecto filosófico distinto del epistémico, un proyecto que tiene su origen en el pensamiento moral de Sócrates, pensamiento desarrollado en diálogos pre-República como la Apología, el Critón y el Gorgias ${ }^{2}$.

En lo que podría denominarse 'ética socrática', expuesta en este grupo de diálogos relativamente tempranos, anteriores al Fedón, se encuentra una idea particularmente revolucionaria respecto a la tradición presocrática y vastamente influyente para toda la tradición filosófica posterior; una idea que dará origen precisamente a lo que aquí voy a llamar, por contraste con el dualismo del Fedón, 'dualismo socrático'. Platón propone por primera vez, en estos diálogos, como fundamento de su filosofía moral, una peculiar conexión entre el comportamiento moral y el alma humana. La pretensión principal de este artículo es exhibir las razones que llevaron al filósofo, en su intento

Cfr. Phd. 73c-77a (especialmente 76d7-e7), 78b-81b, 100a-b.

Esta última concepción dualista está completamente ausente en las interpretaciones canónicas del dualismo platónico. Baste mencionar aquí Long 2015, cap. 3; Rohde 1925, cap. 13; Schnell 1960, cap. 9 (quien llega incluso a atribuir a Sócrates directa y simplemente la teoría dualista del Fedón); Sedley 2009. 
por fundamentar mediante esta peculiar conexión la ética socrática, a postular un igualmente peculiar dualismo entre alma y cuerpo, radicalmente distinto del dualismo tradicional maduro que encontramos en el Fedón.

En la famosa Apología, Platón presenta a Sócrates confrontando una decisión vital. Aquel persistente examen crítico de las convicciones que caracteriza a la actividad socrática es una actividad riesgosa. La examinación socrática ha generado una tremenda hostilidad hacia su persona, pues ha dejado sistemática y públicamente al descubierto la irracionalidad y superficialidad de quienes se han sometido a ella. Esta hostilidad es tal, que ha motivado, según Sócrates, los cargos formales de impiedad y corrupción a la juventud que lo llevan a los tribunales, cargos para los cuales la pena propuesta por la acusación es la pena capital. He ahí que el filósofo se imagine a un objetor preguntándole: ‘¿No te avergüenzas, Sócrates, de haberte dedicado a una ocupación

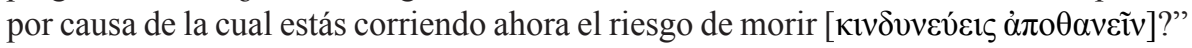
(Ap. 28b 3-5). Parece vergonzoso, indigno de un ciudadano libre, arriesgar la muerte propia -considerada comúnmente como "el peor de los males" (29b1)-mediante una actividad aparentemente tan insignificante, comparativamente, como lo es el examen crítico de las convicciones.

La cuestión vital que debe confrontar Sócrates, según la dramatización de Platón, es la de si acaso continuar con esta actividad examinadora y correr a sabiendas el riesgo de morir como resultado, o abandonar esta actividad para siempre y perpetuar así su propia vida. Sócrates confronta esta vital disyuntiva abordándola desde una perspectiva que sigue sorprendiendo por su radicalidad: ¿Qué ocurre si esta actividad examinadora, aparentemente tan insignificante, tiene una dimensión ignorada por el objetor? ¿Qué ocurre, en particular, si tiene una dimensión moral? Así lo demuestra su respuesta inmediata:

No es correcto lo que dices, si crees que un hombre que vale siquiera un poco

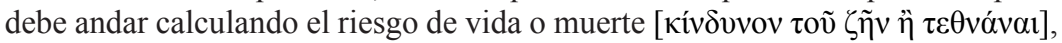
en vez de considerar, cuando obra, tan solo si es justo o no lo que hace, y si sus obras son propias de un hombre recto o vil (Ap. 28b5-9) $)^{3}$.

Según Sócrates, la decisión vital que él confronta pende de una consideración primordial: si acaso su actividad examinadora es justa o no, propia de un hombre recto o vil. En otras palabras, la decisión pende exclusivamente de la dimensión moral de la acción, una dimensión que ha de acallar toda otra, incluido el riesgo de muerte. Si la actividad examinadora - y en general cualquier actividad -resulta ser moralmente recta, el riesgo 
de muerte que ella acarrea debe entonces ser desestimado y no debe contar en contra de su realización. Tal y como Sócrates señala unas líneas más adelante, en tal caso la actividad debe realizarse, "sin tener en cuenta la muerte ni ninguna otra cosa antes que la deshonra" (28d10). Y en efecto, tal actividad de escrutinio resulta ser justa, moralmente recta: es un acto de obediencia a una orden justa dada por un dios justo (28d-29d). Es exclusivamente esta dimensión justa de la actividad la que ha determinado a Sócrates a persistir en ella, sabiendo que corre el riesgo de morir como resultado ${ }^{4}$.

En el Critón, Sócrates confronta otra disyuntiva igualmente vital: escapar de la cárcel contrariando la sentencia de los tribunales, o permanecer en ella dando cumplimiento, dentro de dos días, a la sentencia de muerte. Nuevamente, vemos a Sócrates abordando esta vital disyuntiva desde la misma perspectiva radicalmente moral. La decisión, argumenta el filósofo, pende de una sola consideración primordial:

tenemos que examinar solamente, como decíamos recién, si haremos algo justo al pagarles en dinero y gratitud a quienes me saquen de aquí, y al sacarme tú y escaparme yo, o si en verdad haremos algo injusto al hacer todo eso. Si queda en claro que estaríamos obrando en forma injusta, no debemos tomar en consideración el que, al quedarnos aquí tranquilos, tengamos que morir o sufrir cualquier otra cosa en vez de hacer algo injusto $(\mathrm{Cri} \text {. } 48 \mathrm{c} 7-\mathrm{d} 5)^{5}$.

Esta consideración primordial podría, nuevamente, calificarse de moral, pues consiste en determinar si es justo o injusto fugarse de la cárcel. Si hacerlo resulta ser injusto (i.e. moralmente incorrecto), Sócrates desistirá de fugarse, permaneciendo en la cárcel hasta su muerte.

Platón es plenamente consciente de que para la gran mayoría de la gente existen otras consideraciones, aparte de la dimensión puramente moral de la acción, de las cuales penden decisiones como la que ahora confronta Sócrates en el Critón. La muerte es sin duda la más poderosa de todas, y la que encabeza la lista en estos textos ${ }^{6}$ : si Sócrates permanece en la cárcel, morirá ahora con total seguridad, si escapa, podrá seguir viviendo. En un sentido obvio, si bien hay otras consideraciones independientes de la puramente moral que en el curso de la deliberación práctica pudieran inclinar la balanza a favor de una acción injusta y deshonrosa, o en contra de una acción justa ('tentaciones' y 'riesgos'), la muerte es la más fundamental. Si Sócrates está dispuesto a morir como consecuencia de obrar justamente, a fortiori está dispuesto a perder a sus amistades, a abandonar a sus hijos y a su esposa, a dañar la fama imperecedera de la

4 La misma idea, con la muerte a la cabeza, es reiterada una y otra vez por la Apología: "para que sepan que no haría concesiones a nadie en contra de lo justo por temor a la muerte, y que estaría dispuesto a morir en el acto, con tal de no ceder" (32a6-8). Ver también 32c8d3; 32d1-3; 38e4-5.

$5 \quad$ La traducción es de Gómez-Lobo 1998.

$6 \quad$ Ver nota 4 para la Apología. El Critón menciona a la vida y la muerte como resultados del acto moral, en 46c5, 46d2, 46e3-47a1, 48a11, 48d4, 52c7-8, 53e1, $54 \mathrm{~b} 3$. 
propia persona o de los seres queridos, o a perder sus derechos civiles. Pero no ocurre inversamente de un modo necesario - estar dispuesto a quedar privado de estos bienes, incluso irreparablemente, no implica estar dispuesto a morir.

Pero no: escapar de la cárcel desestimando la sentencia de los tribunales resulta efectivamente injusto, según el argumento del Critón, pues esto significaría quebrantar un contrato justo con el Estado y sus leyes. Una vez más, Platón presenta a Sócrates como un sujeto moral que se deja determinar en el ámbito práctico meramente por la demostrada rectitud de su acción, rectitud que nuevamente acalla aquella otra consideración de tanto peso que es la posibilidad de evitar la muerte que le espera dentro de dos días.

Esta es entonces la tesis que captura la esencia de la ética socrática, y que algunos autores, notablemente Gregory Vlastos, han denominado el principio de la Soberanía de la Virtud". Ninguna de estas consideraciones "tentadoras" extra morales, y por sobre todo la permanencia en la vida, deben determinar la decisión de cómo obrar, piensa Sócrates, si la acción que se contempla involucra cometer injusticia. Por mucho que una acción injusta nos permita preservar alguno de estos bienes como la vida propia, y con ello las amistades o la educación de los hijos, si dicha acción es injusta no debe jamás, bajo ninguna circunstancia, realizarse. Por otro lado, como lo muestra la Apología, si nos encontramos en una situación en que actuar justamente implica el "riesgo" o incluso la certeza de quedar privado de alguno de estos bienes, incluida la vida misma, en tales casos la acción debe realizarse de todos modos. La consideración sobre el aspecto moral de nuestra acción es soberana precisamente en estos sentidos.

Esta tesis, propuesta por Platón en la Apología y el Critón, y como veremos también en el Gorgias, captura la esencia de la ética socrática; pero debido a su radicalidad no es tan fácilmente reconocible por la conciencia moral ordinaria. La conciencia moral ordinaria ciertamente reconoce cuán radical puede ser la exigencia que nos hace la moral, pero tiende a anteponer a ella la prolongación de la propia vida, el instinto primordial de supervivencia. ¿De dónde proviene entonces su justificación? Platón mismo tenía muy claro que la tesis clama por una justificación precisamente porque la inmensa exigencia que proviene de ella, como lo muestra el caso fatal de Sócrates, nos pide sacrificar en aras de la rectitud moral no solamente aquellos bienes mundanos cuyo goce es tan importante para el ser humano -sino incluso la vida misma. De aquí que la tesis de la Soberanía de la Virtud adquiera un tinte suprahumano o heroico. Platón llega así a comparar en la Apología la férrea determinación socrática de seguir examinando a sus conciudadanos por ser esto justo, con la de Aquiles, el gran héroe aqueo que decide vengar la muerte de Patroclo sabiendo que este acto de noble venganza culminará en su propia muerte (cfr. Ap. 28c9-d5).

Pero entonces, ¿qué podría justificar esta sorprendente tesis? ¿Qué propiedad podría tener la justicia e injusticia de una acción que nos obliga a anteponerla tan radicalmente a todo otro beneficio y daño propio, a toda otra tentación o riesgo, incluidas la permanencia en vida y la muerte mismas? La compleja respuesta de Platón a esta

Cfr. Vlastos 1991, p. 210; Gómez-Lobo 1994, p. 76. 
pregunta es igualmente sorprendente, y dará lugar en última instancia a lo que aquí llamaré 'dualismo socrático'.

El primer paso en la justificación de esta tesis sobre la Soberanía de la Virtud lo encontramos en el Critón, y consiste en el desarrollo de lo que aquí llamaré el 'modelo médico' sobre el bien y el mal humanos, por lo cual entenderé en primera instancia una teoría acerca de lo que beneficia y daña al ser humano ${ }^{8}$. El modelo médico aquí inaugurado (Cri.47a13-48a4) consiste en proponer, en primer término, (i) la existencia de un sujeto de beneficio y de daño, es decir, algo que es evidentemente susceptible de ser beneficiado y dañado - a saber, el cuerpo. El modelo asume, en segundo lugar, que (ii) la condición óptima de este sujeto somático de 'cuidado' es la salud, y su condición deteriorada o degradada, la enfermedad; y propone también que existe (iii) un ámbito de actividades que puede beneficiar a este sujeto somático, optimizando su condición

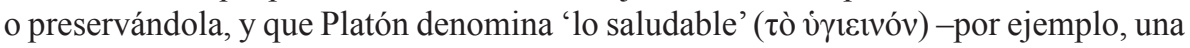
dieta y ejercicio adecuados-así como también uno que puede dañarlo, arruinándolo, y

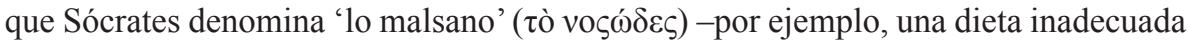
y falta de ejercicio. Finalmente, según este modelo habría (iv) expertos, como el médico o el entrenador físico, que saben en qué medida algo es saludable o malsano para un cuerpo particular, y que tienen por ende la autoridad para aconsejar o educar a un cuerpo determinado.

Este modelo, según el Critón, sirve para iluminar la naturaleza del ámbito de beneficio y daño que podríamos denominar moral -"acerca de las cosas justas e injustas, vergonzosas y nobles, buenas y malas" (Cri.47c9-10). Sócrates sostiene, efectivamente, que existe también aquí un peculiar sujeto de beneficio y de daño moral, enigmáticamente referido como "aquello que se vuelve mejor con lo justo y se arruina con lo injusto" (47d4-5). Sabemos por la Apología que este sujeto, cuya condición es optimizada o preservada por la justicia, así como arruinada o deteriorada por la injusticia, es ni más ni menos que la $\psi v \chi \eta ́$-el alma humana ${ }^{9}$. Análogamente a la aplicación primaria del modelo al caso corporal, Sócrates asume que el alma humana tiene también una condición óptima, una suerte de salud psíquica, y una condición infraóptima de deterioro, una suerte de estado enfermo de índole psíquica. La tesis crucial y sorprendente de Sócrates a este respecto es que la rectitud moral y la inmoralidad, la justicia y la injusticia, adquieren su significancia para la vida humana a partir de la repercusión interna que tienen en la $\psi v \chi \eta ́$ del agente moral mismo, es decir, a partir

8 Entre quienes se han tomado seriamente este modelo como el modelo central de justificación de la ética socrática, puede mencionarse a Santas 1979, cap. VIII. 6, Moravcsik 2000 y Vasilou 2008. Mi reconstrucción difiere de la de estos autores en varios puntos. 


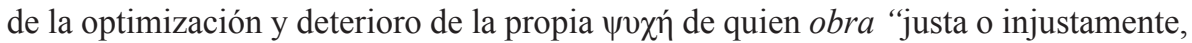
vergonzosa o noblemente" -y esto de un modo análogo a la repercusión que tienen las actividades saludables y malsanas en la condición corporal.

Nótese que, según la aplicación analógica de esta concepción médica al ámbito moral, debe haber una peculiar conexión causal entre la acción moral y el alma humana, tal que la acción moralmente significativa pueda cumplir el papel de contribuir a corromperla o beneficiarla. La naturaleza de esta conexión no está aún clara en el Critón, pues depende en parte de cómo concibamos la naturaleza del alma humana y su condición óptima. Pronto veremos cómo salda Platón esta deuda explicativa.

Ahora bien, esta aplicación analógica del modelo médico al ámbito moral requiere de otra tesis suplementaria. El alma humana, este aspecto del ser humano que es el sujeto de beneficio y daño causado por las cualidades y actividades morales, es algo

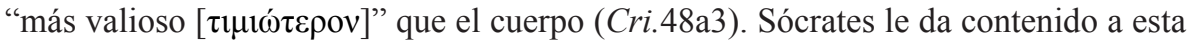
jerarquía superior del alma argumentando que, si es verdad que no vale la pena vivir ${ }^{10}$ con un cuerpo en mal estado y arruinado, entonces vale mucho menos la pena vivir con un alma en mal estado y arruinada ${ }^{11}$. En otras palabras, la valía superior que merece el alma humana por sobre el cuerpo se debe a la manera más pervasiva y profunda en que la condición anímica repercute en la calidad de una vida humana, es decir, en el hecho de que esta vida sea invivible, indigna, soportable o más bien próspera y digna de ser vivida ${ }^{12}$. Este fundamento 'ético' para el estatus superior del alma, no está demás decirlo, es radicalmente distinto del ofrecido por el Fedón, el cual honra al alma exclusivamente por ser la responsable de la aprehensión de las realidades formales -siendo el cuerpo en cambio un obstáculo para dicha aprehensión.

10 Traduzco la frase $\beta \omega \tau$ òv $\dot{\eta} \mu \mathrm{i} v$ غ̇ $\sigma \tau \imath v(C r i .47 \mathrm{~d} 9)$ por 'vale la pena vivir', aunque más literalmente la frase significa 'es vivible por nosotros', donde el sujeto de 'es vivible' es 'la vida'.

11 En rigor, el argumento es el siguiente. Primero, Critón asiente a la afirmación de que (i) no vale la pena vivir con un cuerpo en mala condición y destruido (47e3-5). Luego Critón asiente a la afirmación de que (ii) tampoco vale la pena vivir con un alma destruida o mutilada (47e6-7). Sócrates asume (47e7-48a1) que si la afirmación en (ii) no fuese el caso, entonces (ii*) el alma sería menos valiosa ( $\varphi \alpha v \lambda o ́ \tau \varepsilon \rho o v)$ que el cuerpo -lo cual Critón niega, en paralelo con asentir a (ii)- de suerte que evidentemente asume que la afirmación en (ii) es equivalente a la afirmación (que es la estricta negación de (ii*)) de que (iii) el alma es al menos igualmente valiosa que el cuerpo (i.e. si cualquiera de las dos partes que está en mala condición, no vale la pena vivir). Pero Critón finalmente asiente a la afirmación de que (iv) el alma es más valiosa que el cuerpo (48a3-4). Debido a la equivalencia que Sócrates asume entre (ii) y (iii), se sigue de (iv) que (v): vale menos la pena vivir con un alma en mala condición que con un cuerpo en mala condición.

12 El Gorgias confirmará esta interpretación: los injustos que escapan al castigo disciplinar ignoran "cuánto más miserable que estar asociado a un cuerpo que no está sano, es estar asociado a un alma que no es sana, sino endeble, injusta e impía" (Grg. 479b7-c1; cfr. 511e-512a). 
El modelo médico exige, por lo tanto, no solamente una relación causal entre el acto moral y la condición del alma de un individuo, sino además una conexión entre dicha condición anímica y la vida (ßíos), tal que la condición anímica pueda eventualmente alterar la calidad de una vida humana de un modo más pervasivo, más radical, que la condición corporal. Esta es también una conexión que tendremos que aclarar.

Ahora bien, este argumento que hemos repasado es precisamente el que emplea Platón para respaldar la tesis de la Soberanía de la Virtud. De este argumento se desprende que el foco central de la vida humana debe estar puesto en la acción moral, en tanto que esta afecta (por razones que todavía tenemos que aclarar) la condición interna del alma humana, precisamente aquel aspecto o 'parte' del ser humano cuya condición determina a su vez la propia calidad de vida -tornándola miserable o próspera. Es precisamente debido a esta tremenda importancia que ahora adquiere la acción moral, lógicamente, que la consideración de si acaso lo que nos proponemos hacer es justo o injusto, propio de un hombre recto o abyecto, se vuelve la consideración soberana para el ser humano.

El Gorgias, igualmente comprometido con el principio de Soberanía de la Virtud ${ }^{13}$, profundiza en el modelo médico y lo expande, resolviendo hasta cierto punto las deudas explicativas que han quedado pendientes, tanto aquellas en torno a la naturaleza del alma humana y su conexión con la acción moral, así como aquellas en torno a la jerarquía superior del alma en tanto determinante de la calidad de vida humana. Una vez despejadas estas dudas podremos discernir el modo en que esta estrategia de justificación del principio de Soberanía de la Virtud fuerza a Platón, en los diálogos que ahora nos ocupan, a postular una concepción propiamente dualista sobre la naturaleza del ser humano.

En primer lugar, la existencia de dos sujetos distintos de beneficio y daño que propone el modelo médico -el sujeto somático y el sujeto anímico- sienta ahora las bases, en el Gorgias, para una taxonomía general de las artes ( $\tau \dot{\varepsilon} \chi v \alpha \imath)$ que se ocupan del ser humano, en dos géneros: el género de las artes políticas que rigen sobre el alma, y el género de las artes corporales que rigen sobre el cuerpo ${ }^{14}$. Puesto que están presentes en el ser humano estas dos partes humanas, cada una con su condición

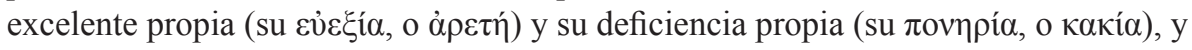
puesto que la condición excelente del sujeto somático está, como ya sabemos, sujeta al cuidado sistemático de las artes de la medicina y el entrenamiento físico, el modelo médico exige naturalmente asignarle también al sujeto anímico un género peculiar de artes que se ocupen de optimizar su condición: las artes políticas.

13 El Gorgias se propone defender la idea de que "el mayor mal es la injusticia y cometer injusticia" (479d1). 
Pero claro, hay dos modos distintos de cuidar de un sujeto de daño y beneficio. Uno puede, en primer lugar, restaurarlo si se encuentra dañado o en mala condición. Esto es lo que hará la medicina con el cuerpo enfermo, y en el caso del alma, lo que hará aquella rama del arte política que es la justicia penal -la encargada de disciplinar y corregir al alma injusta mediante el castigo de un modo análogo a como lo hace el arte médica con el cuerpo enfermo ${ }^{15}$, tanto así que Sócrates describe a la justicia penal

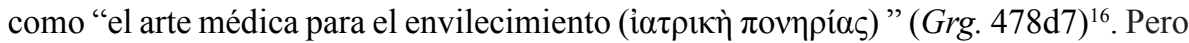
uno puede también cuidar de un sujeto de daño y beneficio de otro modo, de un modo preventivo y regulativo; tal como lo hace el entrenador físico, manteniendo vigoroso al cuerpo adulto ya sano mediante la gimnasia, o entrenando al cuerpo del pupilo para que crezca robusto. De un modo análogo, el arte legislativa mediante leyes justas mantiene al alma justa por el cauce de la justicia, fortaleciendo su condición interna y tornando a los individuos envó $\mu$ นo, " "obedientes de las leyes" (Grg. 504d2).

Vistos ahora estos dos aspectos del ser humano como objetos de cuidado de las artes mentadas, esta perspectiva tiene importantes consecuencias. Al igual que en el Critón, el modelo médico parte del caso evidente del cuerpo y su condición excelente como paradigma del objeto de cuidado, para luego extenderse hacia el alma. Sin duda esto se debe a que el arte de la medicina era ya aclamada, en tiempos de Platón, por haber encontrado ciertos criterios y normas objetivas para la determinación del bienestar de su objeto y de cómo conseguirlo. El concepto de excelencia o buena condición, por lo tanto, tomará como su modelo primario a la salud (v̛rıía), la cual es ahora explícitamente

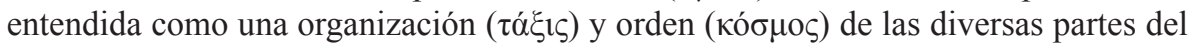
cuerpo: "los que tratan con el cuerpo, como los entrenadores físicos y los médicos, de cierto modo dotan de orden al cuerpo y lo organizan" ${ }^{17}$. Como resultado de este modelo,

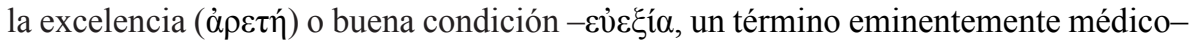
de cada cosa compuesta y susceptible de cuidado, ya sea un cuerpo orgánico, ya un artefacto o un alma, será definida por el Gorgias como "un orden particular, peculiar a cada cosa, que al producirse en cada cosa la hace buena" (506e2-4), y la actividad misma de las artes del cuidado será aquella que "dispone cada cosa en un cierto orden, y constriñe a una parte a que se adecúe y adapte a otra, hasta que logre ensamblar el todo en una obra consolidada y bien ordenada" (503e7-504a1) ${ }^{18}$.

15 Cfr. Grg. 477b-480d, 504d-505b.

16 Las traducciones del Gorgias provienen de Echeñique 2015.

17 Grg. 504a4-5, cfr. 504b9, 504c8. Las teorías sobre la salud del cuerpo biológico que aparecen en el corpus hippocraticum, aunque bastante variadas, sostenían en general que la salud era el estado del cuerpo en que ciertos componentes básicos se encontraban en una proporción relativa adecuada, tanto en cantidad como en potencia, y estaban adecuadamente 'mezcladas'. La enfermedad en general era concebida, por contraste, como un desequilibrio de estas proporciones. Las teorías del corpus difieren en cuanto a la naturaleza de estos componentes básicos, pero como bien señala Santas 1979, cap. VIII. 6, los diálogos tardíos de Platón manifiestan su inclinación por una concepción de la salud como proporción entre los cuatro elementos y sus propiedades.

18 La analogía entre la salud corporal y la anímica reaparece en $R$. 444b-3. 
Como consecuencia de esta perspectiva, el alma humana no puede sino ser concebida como una estructura compuesta de partes, pues solo así puede ella ser objeto del trato correctivo y legislativo propio de las artes políticas. Solo así puede ella mejorar su condición propia, mantenerse vigorosa o deteriorarse y corromperse. En particular, debe ser ella un tipo de estructura compuesta que sea susceptible de recibir educación e instrucción moral, pero sobre todo susceptible de recibir disciplina correctiva, de ser castigada y padecer dolor. Es precisamente porque el alma humana es ahora considerada como el locus donde residen los apetitos biológicos ( $\dot{\varepsilon} \pi \imath v \mu$ ía $)$ como el hambre, la sed y las pulsiones sexuales, todos los cuales miran exclusivamente a su propia satisfacción ilimitada, pudiendo así crecer más de la cuenta y monopolizar la vida humana -tornando al alma, como llega a decir Platón, "purulenta por dentro" (Grg. 480b2)- que la legislación y la disciplina penal deben disciplinarla negándole a estos apetitos gratificación, proveyéndola de planificación y orden e inculcando en ella las excelencias de la justicia y la templanza.

El Gorgias no tiene reparos, en consecuencia, para hablar de "aquella parte del

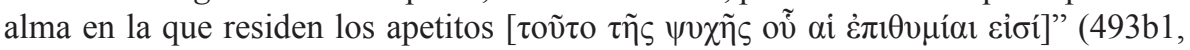
cfr. 493a3-4) ${ }^{19}$. Sabemos, sin embargo, que debe haber al menos otra 'parte' del alma para que esta pueda estar bien o mal ordenada, bien o mal organizada. El diálogo nos da una pista sobre la naturaleza de esta otra parte, cuando inaugura la concepción de la virtud de la templanza ( $\sigma \omega \varphi \rho o \sigma u ́ v \eta)$ con la capacidad para "gobernarse a sí mismo" (491e1), entendida como "el gobierno de los placeres y apetitos que se encuentran en uno mismo" (491d11-e1). Esta otra 'parte' es entonces aquella encargada de gobernar y controlar los apetitos básicos que residen también en el alma humana y de hacerlo en vistas al bien propio.

Los detalles de esta taxonomía anímica y el modo en que será luego elaborada por diálogos posteriores no son ahora mi foco de atención. Lo que me interesa es que el alma deviene en el Gorgias, a raíz de su desarrollo del modelo médico, una estructura compleja consistente de múltiples facultades o 'partes' motivacionales, $-\mathrm{o}$ al menos dos. Sin esta multiplicidad mereológica, las excelencias síquicas como la justicia y la templanza no podrían nunca constituir la condición óptima propia del alma, y el alma humana a su vez no podría ser nunca objeto de cuidado de parte de la legislación y la disciplina correctiva. De acuerdo con esta concepción, además, lo que podría denominarse 'la vida moral' del ser humano se ha vuelto completamente internalizada. Las excelencias morales - la justicia y la templanza en particular-son ahora concebidas precisamente como aquellas disposiciones de estas partes anímicas que dotan al alma de un arreglo ordenado y harmónico interno.

Tal vez estemos ahora mejor situados para comprender las razones que conducen a Platón a atribuirle a la condición anímica el rol de determinar la calidad de una

19 Ver Dorion 2012 para una defensa del uso del lenguaje de "partes" al traducir estos pasajes, y en general para una defensa de que el Gorgias propone una concepción bipartita del alma humana. 
vida humana. Para Platón es casi una tautología, por decirlo así, atribuirle al alma el principio de la vida ${ }^{20}$, aunque la vida que aquí se debe a la presencia del alma en un cuerpo es eminentemente un estado biológico, en la medida en que contrasta con el de estar muerto ${ }^{21}$. Cuando, en cambio, Platón habla de una vida excelente, o de vivir felizmente ${ }^{22}$, aquí el concepto de vida no es biológico. La noción de 'vida' aquí pasa a significar algo así como el conjunto de actividades propiamente humanas, que definen al ser humano. En cierta medida, la tendencia de Platón a partir del Gorgias es extender la conexión conceptual inicial que tiene el alma con la vitalidad, a la 'vida' en este segundo sentido. Si seguimos la lógica sugerida implícitamente por el Gorgias, y solo desarrollada explícitamente por diálogos posteriores, la condición del alma humana resulta ser la de todos los estados anímicos que caracterizan la vida propiamente humana tal y como la conocemos -en palabras de las Leyes, procesos como "querer, examinar, cuidar, deliberar, opinar correcta o erróneamente, alegrarse, afligirse, atreverse, temer, odiar, amar" (897a1-3). Son estas actividades síquicas cuyo arreglo u orden, fruto de las excelencias morales, determinan la calidad de una vida humana ${ }^{23}$.

¿Pero qué ocurre con la acción moral, según este modelo? Toda esta disquisición ha sido motivada por la exigencia de fundamentar la soberanía de la acción moral, que es la que está en juego en las situaciones de vida o muerte que enfrenta Sócrates en la Apología y el Critón. Vimos que hasta el momento el modelo médico no ha dado respuesta a esta soberanía de la acción moral-solamente sabemos que ante todo debemos cuidarnos de ser personas justas, templadas. ¿Cómo es posible que la acción moral beneficie o dañe al alma humana, como suponía el Critón?

Todo indica que los diálogos socráticos ofrecen dos respuestas a esta pregunta. Una respuesta propone la identidad entre obrar justamente y ser una persona justa. Así, por ejemplo, en el Gorgias encontramos no solamente la afirmación de que "la persona justa presumiblemente realiza acciones justas" (460b8); también encontramos la tesis conversa, mucho más controversial: "Quien realiza acciones justas y piadosas es preciso que sea justo y piadoso" (507b3-4). Sin embargo, lo que Platón necesita es más bien una tesis que relacione causalmente a la acción moral con la excelencia o deficiencia moral propia del alma, de un modo análogo a como 'lo saludable' y 'lo malsano' generan salud y enfermedad en el cuerpo, y ayudan a mantener estos estados. El Gorgias mismo ofrece para estos efectos algo así como una proto-teoría de la habituación moral, pues se refiere a las excelencias y deficiencias del alma humana como "afecciones que el ser humano adquiere en su alma debido al cultivo ( $\dot{\pi} \pi \imath \dot{\delta} \delta \varepsilon v \sigma \iota \varsigma)$ de cada una de sus

20 Cfr. Phd. 105d; Leg. 895c7-10.

$21 \quad$ Cfr. Ap. 28b7; Grg. 483b2; Phd. 71d6.

22 Por ejemplo: $\tau$ ò

23 La salud y vitalidad corporales (junto quizás con la belleza), quedan relegadas meramente al estatus de un bien condicionado por un arreglo óptimo de la vida síquica: el tipo de ítem no-moral que puede admitirse genuinamente como un bien (cfr. Cri. 47d-e; Grg. 467e3; Euthd. 279a-b; Men. 78c), como algo que contribuye a la vida feliz, solamente en la medida en que es "utilizado" por las excelencias morales. Sobre este punto, ver Vlastos 1991. 
prácticas" (524d6-7) -como afecciones estables en las que "uno puede entrenarse"

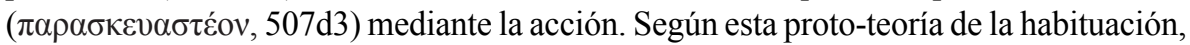
la acción moral, ya sea esta justa o injusta, intemperante o templada, noble o vergonzosa, es el origen causal de la condición excelente o deficiente del alma humana, condiciones que a su vez son consideradas como "cultivables" o "entrenables" mediante la acción moral $^{24}$. El acto moral contribuye así al cultivo de las excelencias o deficiencias morales, generándolas mediante su práctica habitual, manteniéndolas robustas o, eventualmente, degradándolas $-\mathrm{y}$ con esto beneficiando o dañando al alma misma ${ }^{25}$.

Ahora bien, ¿qué relación guarda todo esto con el dualismo metafísico? Hasta el momento, ningún elemento del modelo médico que hemos examinado exige que el alma y el cuerpo puedan o deban ser dos entidades capaces de existencia individual y separada. En particular, nada sugiere hasta ahora que el alma, concebida como la estructura compleja de partes motivacionales susceptibles de ordenamiento interno, pueda ni mucho menos deba existir separada de su unión con el cuerpo, y sobrevivir a la muerte biológica. Debemos recordar en este punto qué ha llevado a Platón a desarrollar este modelo médico de dos sujetos independientes de daño y beneficio presentes en el ser humano: es un modelo para justificar la tesis de la Soberanía de la Virtud. Todo parece sugerir que el modelo médico cumple ya a cabalidad esta función justificadora, sin la postulación de un dualismo metafísico propiamente tal. La tesis de que el alma humana es un sujeto independiente de beneficio y daño -independiente, esto es, del sujeto somático- solo implica que su excelencia propia, junto con sus condiciones de realización, es un estado causalmente independiente de la excelencia corporal. Pero esto no implica que el alma humana misma pueda o deba existir separada del cuerpo humano.

Lo que quiero sugerir ahora es que Platón, quizá gradualmente, se fue dando cuenta en estos diálogos como la Apología, el Critón y el Gorgias, de que esta estrategia de defensa de la soberanía de la acción moral adolecía de un grave problema; un problema que solo podía resolverse internamente, sin abandonar la estrategia del modelo médico, postulando precisamente la supervivencia del alma humana a la muerte biológica del cuerpo.

Para apreciar el problema en cuestión, es menester volver a enfatizar que las situaciones prácticas en las que Sócrates pone en marcha su principio de Soberanía de la Virtud son situaciones de vida o muerte. Son situaciones prácticas en las que el riesgo

$24 \quad$ Sigo aquí la sugerencia de Vasilou 2008, cap. 3.8.

25 Esta proto-teoría de la habituación se encuentra bien plasmada en República IV, donde Platón describe así a la persona justa como quien "tendrá por justa y bella -y así la denominarála acción que preserve este estado del alma y ayude a su producción... Por el contrario, considerará injusta la acción que disuelva dicho estado anímico..." (443e5-444a1). 
que se corre mediante la acción moral es el de morir -riesgo que se hace inminente durante el juicio y al que se alude obsesivamente en la Apología, y uno que se vuelve ya una certeza en la cárcel, como recalca una y otra vez el Critón. El problema es que ante este riesgo particular que es el de morir, la defensa que hemos visto del principio de Soberanía de la Virtud, en base al modelo médico, resulta altamente cuestionable y frágil.

Dicha defensa presupone que la acción moral, recta o deshonrosa, tiene precedencia absoluta por sobre cualquier otra tentación o riesgo que con ella se incurra-incluido el riesgo de muerte o la tentación de preservar la vida-debido a su conexión causal con la condición del alma humana. Es la acción justa o injusta la que beneficia o daña al alma humana, determinando así la calidad de una vida humana. Quiero aquí sugerir, sin embargo, que Platón se dio eventualmente cuenta de que cuando la acción moral acarrea la muerte propia, esta justificación de la exigencia de realizarla o evitarla a toda costa pierde validez. Y la razón es esta: Cuando uno ha muerto, es decir, cuando aquel sujeto tan venerable y preciado de beneficio que es el alma ya no está allí para ser beneficiado por la acción justa, entonces desaparece eo ipso la exigencia de realizar dicha acción a toda costa, según el modelo médico de justificación.

El problema surge más claramente en casos de muerte heroica, como la de Aquiles, donde el último acto de la vida del héroe es un acto justo que culmina en la propia muerte. Un acto justo que podríamos decir tiene un 'carácter fatídico'. El héroe muere vengando la muerte de Patroclo, sabiendo de antemano que su venganza acarrearía "inmediatamente" (Ap. 28d2) su muerte. Indudablemente que para el código moral arcaico era perfectamente posible justificar esta fatídica acción apelando a conceptos como el de la estima inter pares, o la gloria alcanzada mediante el acto heroico. Estos conceptos le permitían al héroe en cierto modo inmortalizarse mediante su sacrificio heroico - preservando su fama en la memoria de los mortales, o en el poema mismo. Pero claro, ninguno de estos mecanismos de 'supervivencia' se encuentra disponible en la ética socrática, la cual por el contrario se opone a toda forma externa o socializada de dotar de valor y justificación al acto moral ${ }^{26}$. Para la ética socrática, como ya sabemos, el valor de la acción moral radica en su repercusión interna en el alma, y la calidad de vida, del agente mismo. Pero entonces, si asumimos que la muerte implica la destrucción del alma, ¿de dónde puede provenir la exigencia de realizarla, en el ejemplo de Aquiles? Ya no puede provenir de la capacidad de la acción de beneficiar al alma -lo cual asume que el alma siga allí para recibir el beneficio del acto-pues ex hypothesi este sujeto de cuidado ya no existe.¿Cómo entonces justificar en estos casos fatídicos la exigencia soberana de realizar la acción justa antes que evitar la muerte?

Sin duda, Platón estaba ya tempranamente consciente de este problema. $\mathrm{Su}$ solución inicial a este pareciera acentuar una característica peculiar a la exigencia presente en el caso socrático: la exigencia de realizar la acción recta, antes que evitar

26 Todavía Jenofonte apela ingenuamente a la gloria $(\varepsilon v ̋ \kappa \lambda \varepsilon 1 \alpha)$ alcanzada por Sócrates mediante la probidad de su defensa y la actitud ecuánime ante la sentencia de muerte (Mem. 4. 8. 1). 
la muerte obrando inmoralmente. En efecto, la Apología (29a4-b10) argumenta que ante dos opciones prácticas excluyentes, A y $\mathrm{B}$, si uno sabe que $A$ es mala y uno no sabe si B es buena o mala, uno debe rehuir A en lugar de rehuir B. Puesto que Sócrates sabe que cometer injusticia es malo y que al cesar de examinar a sus conciudadanos cometería injusticia, mientras que no sabe si la muerte es un mal o un bien, debe él continuar examinando a sus conciudadanos - evitando así un daño a sabiendas-antes que evitar la muerte -que no sabe si es o no un mal-mediante la cesación de dicha actividad. En realidad, esta supuesta solución no resuelve realmente el problema en cuestión, el cual surge tanto para la acción moralmente recta considerada un beneficio para el agente, como para la misma considerada como evasión de un daño: si el agente muere, solo se le evitará un daño en el sentido trivial de que no habrá un sujeto al cual dañar - pero tampoco habrá sujeto al cual evitarle daño.

Debido entonces a este problema presentado por decisiones morales de carácter fatídico, quiero sugerir que Platón cayó eventualmente en la cuenta de que una justificación exhaustiva del principio de Soberanía de la Virtud requería postular la sobrevivencia del alma a la muerte biológica, la persistencia post mortem del sujeto síquico de beneficio y daño, pues solamente mediante tal postulado podría justificarse la exigencia de realizar la acción moral ante la certeza de muerte inminente en casos fatídicos como aquellos confrontados por Sócrates en la Apología y en el Critón. Eventualmente, Platón se dio cuenta de que si asumimos que aquel preciado sujeto de cuidado que es el alma, en cuyo beneficio y daño radica la soberanía de la acción moral, persiste después de la muerte, la última acción moral puede preservar, no obstante su carácter fatídico, la capacidad de daño y especialmente, de beneficio -y la vida que ella coronó puede ser descrita como una vida "que inclusive hasta el otro mundo sigue siendo manifiestamente beneficiosa" (Grg. 527b1-2).

Es así que Platón llega a adoptar, en el Gorgias, una concepción de la muerte paralela a la que encontramos en el Fedón:

La muerte viene a ser, según mi opinión, nada más que una separación recíproca de dos cosas, del alma y del cuerpo; pero una vez que fueron separadas la una de la otra, pareciera que cada una de ellas retiene sin mucha pérdida aquella condición propia que tenía cuando el ser humano estaba vivo (Grg. 524b2-6).

Según esta concepción de la muerte, lo que ocurre al momento de morir es que aquellos dos aspectos del ser humano que antes se encontraban en cierto modo unidos, conformando una vida humana, se separan el uno del otro. Pero a pesar de que el Fedón propone la misma definición de muerte, como una separación del alma del cuerpo (64c4-5), este diálogo no sostiene la supervivencia íntegra del sujeto de beneficio y daño, como sí lo hace el Gorgias. El alma que, según este diálogo, debemos asumir sobrevive a su separación del cuerpo, no puede ser pura inteligencia, pues debe continuar siendo aquel mismo sujeto de cuidado que las acciones morales del individuo afectaban en vida. En esta concepción dualista de corte "socrático", el alma post mortem debe preservar en ella todo el complejo arreglo de elementos síquicos que la caracterizaban, y en particular las disposiciones excelentes o deficientes que han sido producto del cultivo y habituación práctica en vida: "Todo sigue siendo visible en el alma cuando se despoja del ropaje del 
cuerpo, tanto sus atributos naturales como las afecciones que el ser humano adquirió en su alma debido al cultivo de cada una de sus prácticas" (Grg. 524d4-7, cfr. 525a). En otras palabras, el alma debe sobrevivir, en esta concepción 'socrática', preservando la condición moral que la caracterizaba en vida, pues esta es la condición en la cual el último acto moral, fatídico, puede ahora repercutir.

Esta interpretación del rol que cumple el postulado de la supervivencia del alma en su condición moral para la fundamentación de la ética socrática, según la cual dicho postulado sería una pieza esencial para dicha fundamentación, es por supuesto controversial, y ha sido explícitamente rechazada por algunos intérpretes ${ }^{27}$. No puede ser una mera coincidencia, sin embargo, que esta concepción moral del alma post mortem sea precisamente la que presentan los tres diálogos donde se defiende la tesis de la soberanía del acto moral. Es fácil apreciar el modo en que dicha concepción va ganando cada vez más terreno, siendo por primera vez anunciada tímidamente en la Apología, en la forma de una mera posibilidad de "una suerte de cambio de estado y migración del alma desde este lugar de aquí hacia otro sitio" (40c7-9), para luego ser dogmáticamente asumida en la sección final del discurso de las Leyes en el Critón (54b-d), siendo finalmente propuesta con cierta seguridad -como una verdad-en la narración escatológica que da cierre al argumento del Gorgias $^{28}$.

Se me podría objetar que estas concepciones escatológicas de la vida post mortem del alma, sobre todo las que cierran el Critón y el Gorgias, solamente introducen la supervivencia del alma que preserva su condición moral con el propósito de hacerla susceptible de enjuiciamiento divino por parte de los jueces del inframundo. Este enjuiciamiento es a su vez introducido por Platón al final de estos diálogos como -en palabras de Grube- un "aliciente adicional" para la vida moralmente recta ${ }^{29}$, de suerte que el postulado de supervivencia anímica no sería una pieza esencial del modelo moral socrático. Platón quiere hacernos pensar que los jueces del inframundo enjuician, y eventualmente castigan por su vida terrena a las almas humanas apoyándose precisamente en la condición moral que ellas aún preservan, condición que puede ser fácilmente detectada ahora que las almas se han desprendido de todo el ropaje del cuerpo. Si el postulado de supervivencia está meramente supeditado a este "aliciente adicional" para

$27 \quad$ En palabras de Enmark: "neither does the belief that the moral self of man is undestroyable form a necessary postulate for the argumentation of Socrates, even if such a belief would strengthen it" (Ehnmark 1946, pp. 114-115). También Grube: "That the soul is immortal appears from the myth of the day of judgement at the end of the Gorgias, but it should be understood that Socrates' arguments for the good life are in no way based upon it in the first instance and that, here as elsewhere, his ethical system stands even if this immortality is denied. The myth is an addendum, not an argument. At least until in his later dialogues immortality followed from premises he had by then worked into his philosophy, Plato was inclined not to treat the belief in it as a main argument for, but only as an added aducement to, the good life" (Grube 1980, p. 124).

28 Cfr. Grg. 523a1-3, 524b1.

$29 \quad$ Ver nota 27. 
la vida recta, entonces pareciera no haber buenas razones para pensar que el postulado de supervivencia anímica a la Sócrates es introducido por Platón para solucionar el problema de los casos fatídicos de acción moral.

Si bien esta objeción no puede ser ignorada, dista mucho de ser definitiva. Lo esencial acerca de estas concepciones escatológicas, según la interpretación aquí defendida, es introducir en el argumento socrático la asunción de que el alma continúa teniendo una cierta vida moral después de la muerte. El hecho de que sobre la base de esta asunción Platón pueda construir la concepción de un enjuiciamiento divino post mortem como una exhortación a la buena vida terrena, no implica que la asunción misma esté meramente supeditada a este elemento exhortativo. Por el contrario, podría argumentarse que la idea de dicho enjuiciamiento a las almas es la concepción más plausible y ordinariamente aceptable que tenía Platón a su disposición para hacer sentido de algo así como una vida moral después de la muerte. Que la concepción de un juicio divino post mortem está más bien supeditada a este fin, lo sugiere el intento de Platón por forzarla a acomodarse a dicho fin. Esto ocurre, por ejemplo, cuando el Gorgias introduce la idea de un castigo divino a las almas curables, rehabilitables (cfr. Grg. 525b). No es fácil comprender cómo pueden castigos rehabilitadores y disuasivos (como los que Platón concibió) tener efecto en el mundo post mortem, cuando los individuos ya han tomado las decisiones cruciales para sus vidas terrenales -a no ser que el alma siga viviendo una vida moral en algún sentido en el inframundo, tomando decisiones vitales, ganando experiencia moral, etc.

Si bien una defensa exhaustiva de la ética socrática requiere, como Platón mismo logró darse cuenta, de la asunción de supervivencia del alma en su calidad de sujeto de cuidado, esta asunción dualista nunca logra alzarse al estatus de una tesis filosófica explícita, defendida mediante argumentos racionales. Sin embargo, si mi interpretación es correcta, el estatus epistémico de dicha asunción, en cuanto postulado necesario para completar la defensa de la moral socrática, no es radicalmente distinto al estatus que la tesis dualista detenta en el Fedón, donde la existencia separada del alma humana funciona como un postulado que necesariamente ha de añadirse a la admisión de la existencia de realidades formales y de la posibilidad del conocimiento formal que las tiene por objeto.

Eventualmente, Platón se dio cuenta de que este postulado dualista de corte socrático era indefendible filosóficamente, incapaz de resistir un escrutinio racional. Platón se torna claramente consciente, en el Fedón-y más tarde también en la República-de que si el alma ha de sobrevivir a su separación del cuerpo, ella no puede ser un compuesto de partes - por el contrario, debe ser algo simple, en rigor indivisible. Ya sabemos cómo el Fedón desarrolla esta idea, definiendo al alma por su facultad intelectiva, una facultad indivisible y simple al igual que sus objetos formales. Pero ahora es igualmente evidente que esta concepción dualista más madura ya no puede a su vez ser puesta al servicio de una fundamentación de la ética socrática. Al estar meramente caracterizada 
por la facultad intelectiva, el alma ya no puede ser un sujeto de daño o beneficio moral, ya no puede ser el tipo de entidad en cuya condición repercute causalmente la acción $\operatorname{moral}^{30}$. Platón debe por lo tanto abandonar el intento de fundamentación de la ética socrática por la vía del postulado de un sujeto moral superviviente, y abandonar con esto también la moral socrática misma cuya esencia es el principio de Soberanía de la Virtud -un principio que ahora desaparece de los diálogos platónicos.

\section{Referencias bibliográficas}

Dorion, Louis-André (2012), "Enkrateia and the partition of the soul in the Gorgias", en R. Barney, T. Brennan, Charles Brittain, eds., Plato and the Divided Self. Cambridge: Cambridge University Press; pp. 33-52.

Ehnmark, Erland (1946), "Socrates and the Immortality of the Soul", Eranos 44: 105122.

Echeñique, Javier (2015), Platón, Gorgias. Santiago de Chile: Editorial Universitaria. Gómez-Lobo, Alfonso (1994), La Ética de Sócrates. Santiago de Chile: Editorial Andrés Bello.

(1998), Critón. Santiago de Chile: Editorial Universitaria.

Grube, G. M. A. (1980), Plato's Thought. London: Hackett.

Long, Anthony, A. (2015), Greek Models of Mind and Self. London: Harvard University Press.

Moravcsik, Julius (2000), "Health, Healing, and Plato's Ethics”, Journal of Value Inquiry 34: 7-26.

Rohde, Erwin (1925), Psyche: The Cult of Souls and the Belief of Immortality among the Greeks. New York: Routledge.

Santas, Gerasimos (1979), Socrates. London, New York: Routledge.

Sedley, David (2009), “Three kinds of Platonic inmortality”. En D. Frede, B. Reis, eds., Body and Soul in Ancient Philosophy. Berlin, New York: Walter de Gruyer; pp. 145-172.

Schnell, Bruno (1960), The Discovery of the Mind. New York: Dover Publications.

Vasilou, Iakovos (2008), Aiming at Virtue in Plato. Cambridge: Cambridge University Press.

30 Sobre este punto vale la pena citar a Sedley: "According to the Phaedo, everything composite can eventually come apart, and the reason why souls, like Forms, are privileged with indissolubility is that they are incomposite $(78 \mathrm{~b} 4-80 \mathrm{~b} 11)$. Once Plato arrived at his theory that the soul consists of three parts, as he did in the Republic, he had to consider seriously (R. 10, 611b5 -7) the need to restrict immortality to just one of those parts, namely reason, the part most closely corresponding to the whole soul as conceived in the earlier Phaedo". (Sedley 2009, p. 155). 
Vigo, Alejandro (1998), Apología de Sócrates. Santiago de Chile: Editorial Universitaria.

Vlastos, Gregory (1991), "Happiness and virtue in Socrates' moral theory". En G. Vlastos, ed., Socrates: Ironist and Moral Philosopher. New York: Cornell University Press; pp. 200-232. 